\title{
Transapical and transaortic transcatheter aortic valve replacement: Still part of the game and at what cost?
}

\author{
Jessica Forcillo, MD, MSc, ${ }^{\mathrm{a}}$ and Vinod H. Thourani, $\mathrm{MD}^{\mathrm{b}}$
}

\footnotetext{
From the a Department of Cardiac Surgery, Centre Hospitalier de l'Universite de Montreal (CHUM), Montreal, Quebec, Canada; and ${ }^{\mathrm{b}}$ Department of Cardiac Surgery, Medstar Washington Hospital, Washington, DC. Disclosures: Authors have nothing to disclose with regard to commercial support.

Received for publication May 30, 2017; accepted for publication May 31, 2017; available ahead of print July 12 , 2017.

Address for reprints: Vinod H. Thourani, MD, Department of Cardiac Surgery, Medstar Washington Hospital, 110 Irving St, Suite 6D, Washington, DC 20010 (E-mail: vhthourani@gmail.com).

J Thorac Cardiovasc Surg 2017;154:1233-4

$0022-5223 / \$ 36.00$

Copyright (c) 2017 by The American Association for Thoracic Surgery http://dx.doi.org/10.1016/j.jtcvs.2017.05.096
}

It has become quite evident that transcatheter aortic valve replacement (TAVR) has become a well-accepted treatment strategy for extreme-, high-, and some intermediate-risk patients with severe aortic stenosis. ${ }^{1-5}$ Although at one time the rate of transfemoral (TF) and transapical (TA) TAVR were similar, the advent of the newest generations of transcatheter heart valves clearly have moved the pendulum to more than $90 \%$ using the $\mathrm{TF}$ approach. Moreover, alternative routes have expanded from just TA to transaortic (TAo), transcarotid, trans-subclavian, suprasternal, or transcaval approaches. The choice of the alternative access used, if transfemoral TAVR is not possible, remains at the discretion of the operator who performs the procedure and his or her level of ease with the procedure chosen.

However, a handful of randomized data have assessed alternative accesses versus the most common approach used, the transfemoral approach. In the major trials published on TAVR, such as the Placement of Aortic Transcatheter Valves (PARTNER) 1A and 2A trials, the comparisons between the TF group and the alternative-access group were performed mainly as part of a subanalysis and not powered to detect statistical significant differences, and the results were then only suggestive. ${ }^{2,3}$ However, retrospective studies have been performed that compare TF and individual alternative approaches and did demonstrate that in an experienced multidisciplinary heart team, either access route could be performed with similar clinical outcomes. ${ }^{6-8}$ However, in a propensity-matched series of the PARTNER 1 study, Blackstone and colleagues ${ }^{8}$ did report worse outcomes in TA compared with patients undergoing TF.

In the current paper by McCarthy and his colleagues ${ }^{9}$ from the University of Pennsylvania, the authors reported a greater 30-day mortality among patients who underwent a TA or TAo TAVR compared with TF TAVR. TA also was associated with increased mortality compared with TAo (odds ratio $1.59, P<.01$ ). This finding could be due to the fact that more patients in the TA group required the use of cardiopulmonary bypass, which was found to be a strong predictor of 30-day mortality in

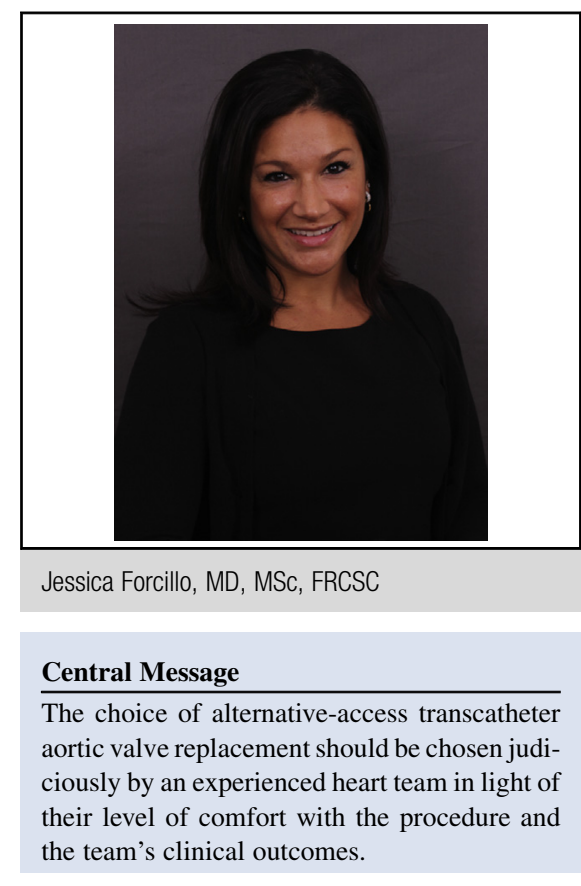

See Article page 1224.

the logistic regression analysis (odds ratio 5.17, $P<.01)$. However, in a retrospective study using the US Society of Thoracic Surgeons/American College of Cardiology Transcatheter Valve Therapies database, we compared transapical and transaortic TAVR outcomes and showed that there were no risk-adjusted differences between TA and TAo in mortality, stroke, or readmission rates at 1 year after TAVR. ${ }^{6}$

Although the clinical benefits of TAVR clearly have been shown in multiple randomized trials, this novel technology remains expensive. To date, no studies have evaluated the cost related to TF compared with alternative-access TAVR. We congratulate the authors on this very novel aspect to their contribution. They have demonstrated that hospital costs and Medicare payments varied by TAVR access, with TF having the lowest of both, $\$ 48,600$ (interquartile range $\$ 37,800-\$ 62,900)$ and $\$ 50,100 \quad(\$ 38,300$ $\$ 65,600)(P<.01)$, respectively. This difference is not statistically significant at 90 days $(P=.08)$, but, once again, this difference in cost at 30 days could be driven by the use of more medical supplies and human resources while using cardiopulmonary bypass. For instance, it may be that the TF TAVRs were performed in the catheterization laboratory with little postoperative intensive care stay 
compared with the alternative access in the hybrid room under general anesthesia.

The choice of access has evolved since our first use of TAVR in the United States in 2007. The shift from 55\% TF usage to now more than $\sim 90 \%$ is evident by the improved technology allowing a less-invasive option for aortic valve replacement. It remains extremely difficult to compare TF with TA or TAo TAVR, since the alternativeaccess patients are generally those who are not candidates for femoral access. It remains important for an institution performing TAVR to be facile in TF and at least 1 to 2 other alternative access procedures; in our case, we have migrated to the transcaval and transsubclavian techniques. This will allow an experienced heart team to perform the most optimal, patient-centered TAVR procedure.

\section{References}

1. Leon MB, Smith CR. Transcatheter aortic-valve replacement. N Engl J Med. 2016; 375:700-1.

2. Mack MJ, Leon MB, Smith CR, Miller DC, Moses JW, Tuzcu EM, et al. 5-year outcomes of transcatheter aortic valve replacement or surgical aortic valve replacement for high surgical risk patients with aortic stenosis (PARTNER 1): a randomised controlled trial. Lancet. 2015;385:2477-84.

3. Kapadia SR, Leon MB, Makkar RR, Tuzcu EM, Svensson LG, Kodali S, et al. 5year outcomes of transcatheter aortic valve replacement compared with standard treatment for patients with inoperable aortic stenosis (PARTNER 1): a randomised controlled trial. Lancet. 2015:385:2485-91.

4. Thourani VH, Kodali S, Makkar RR, Herrmann HC, Williams M, Babaliaros V, et al. Transcatheter aortic valve replacement versus surgical valve replacement in intermediate-risk patients: a propensity score analysis. Lancet. 2016;387:2218-25.

5. Reardon MJ, Van Mieghem NM, Popma JJ, Kleiman NS, Søndergaard L, Mumtaz M, et al. Surgical or transcatheter aortic-valve replacement in intermediate-risk patients. $N$ Engl J Med. March 17, 2017 [Epub ahead of print].

6. Thourani VH, Jensen HA, Babaliaros V, Suri R, Vemulapalli S, Dai D, et al. Transapical and transaortic transcatheter aortic valve replacement in the United States. Ann Thorac Surg. 2015;100:1718-26; discussion 1726-7.

7. Schymik G, Heimeshoff M, Bramlage P, Herbinger T, Würth A, Pilz L, et al. A comparison of transcatheter aortic valve implantation and surgical aortic valve replacement in 1,141 patients with severe symptomatic aortic stenosis and less than high risk. Catheter Cardiovasc Interv. 2015;86:738-44.

8. Blackstone EH, Suri RM, Rajeswaran J, Babaliaros V, Douglas PS, Fearon WF, et al. Propensity-matched comparisons of clinical outcomes after transapical or transfemoral transcatheter aortic valve replacement: a placement of aortic transcatheter valves (PARTNER)-I trial substudy. Circulation. 2015;131:1989-2000.

9. McCarthy FH, Spragan DD, Savino D, Dibble T, Hoedt AC, McDermott KM, et al. Outcomes, readmissions and costs in transfemoral and alterative access transcatheter aortic valve replacement in the US Medicare population. J Thorac Cardiovasc Surg. 2017;154:1224-32.e1. 